\title{
PKM PEMBERDAYAAN KELOMPOK PETANI KAKAO MELALUI PENERAPAN METODE SLPHT DI DESA SIBALAGO KECAMATAN TORIBULU KABUPATEN PARIGI MOUTONG
}

\author{
Kasman Jaya $^{1^{*}}$, Hasmari Noer ${ }^{1}$ \\ ${ }^{1}$ Program Studi Agroteknologi, Fakultas Pertanian, Universitas Alkhairaat \\ Jln. Diponegoro No. 39 Palu 94221 Sulawesi Tengah Indonesia \\ e-mail: kasmanjsaad@yahoo.co.id
}

\begin{abstract}
ABSTRAK
Tujuan kegiatan PKM ini adalah 1. Meningkatkan produksi kakao melalui transformasi teknologi pemeliharaan kakao diantaranya melalui konservasi lahan dengan penggunaan pupuk organik, pengendalian busuk buah dan penanganan pasca panen dengan fermentasi. 2. Meningkatkan kualitas dan mutu kakao yang memiliki daya saing, dengan menerapkan bahan organik sehingga tidak terdapat residu bahan kimia, agar produk tersebut dapat bersaing dengan kualitas ekspor. 3. Melakukan pembinaan kepada anggota kelompok tani mitra agar dapat meningkatkan produksi dan kualitas pupuk organik padat dengan bahan dasar pemanfaatan kulit buah kakao yang ditambahkan dengan jamur Trichoderma sp dapat mempercepat proses dekomposisi, sehingga dapat tersedia pada saat yang diharapkan. 4. Meningkatkan kemampuan petani dalam penguasaan asset produksi, modal, dan pasar agar dapat menerapkan paket teknologi inovatif terpadu. 5. Meningkatkan pendapatan masyarakat petani agar masyarakat petani lebih sejahtera, serta merubah Mindset petani menjadi manusia yang produktif dan berkarya. Metode yang diterapkan dalam mencapai target dan penyelesaian masalah dari program PKM ini, adalah metode pendidikan masyarakat dengan pendekatan Participatory Rural Appraisal (PRA/RRA). Penerapan metode pelatihan (training) bertujuan untuk peningkatan kemampuan sumber daya manusia secara individu dan kelompok; Peningkatan kualitas kebun contoh melalui metode sekolah lapang, demonstrasi demplot percobaan dengan menerapkan Teknologi Pengendalian Hama Terpadu, Teknologi Perbanyakan Semut, Teknologi Bioinsektisida Berbahan Aktif Beauveria bassiana dan Trichoderma sp dan Teknologi pupuk organik. Hasil yang dicapai berupa 1. Peningkatan pemahaman kepada kelompok Mitra untuk dapat mengetahui tentang rehabilitasi tanaman kakao, pengendalian OPT yang sesuai dengan prinsip-prinsip PHT, dengan keterampilan yang dimiliki dalam memperbanyak jamur trichoderma sp dan memperbanyak semut hitam di lapangan. 2. Peningkatan pengetahuan dan keterampilan dalam pembuatan pupuk organik dengan pemanfaatan limbah kakao dengan menambahkan dekomposer jamur trichoderma sp untuk mempercepat proses dekomposisi. 3.Meningkatnya produksi kakao karena adanya penguasaan teknologi pemeliharaan kakao secara terpadu. 4. Peningkatan pemahaman tentang dampak penggunaan pestisida secara berlebihan, dan adanya solusi alternatif pengendalian OPT yang lebih ramah lingkungan.
\end{abstract}

Kata kunci: Pengendalian OPT, Kakao, Pemberdayaan, Trichoderma sp , Metode SLPHT

\section{Pendahuluan}

Kecamatan Toribulu merupakan salah satu kecamatan di Wilayah Kabupaten Parigi Moutong yang memiliki luas lahan tanaman kakao mencapai 3.078 hektar dengan jumlah tanaman 145.274 pohon dengan total produksi 2.445 ton yang dikelola oleh 3.079 KK dengan produktifitas $898 \mathrm{~kg} / \mathrm{ha} / \mathrm{th}$. Desa Sibalago Kecamatan Toribulu adalah satu dari sekian banyak desa yang ada diwilayah Kabupaten Parigi Moutong, memiliki luas tanaman kakao sebanyak 232 ha yang terbagi dalam 9 kelompok tani yang tergabung dalam GAPOKTAN Bina Karya Bakti. Meskipun kakao di Kabupaten Parigi Moutong merupakan komoditi unggulan dengan produksi yang masih tinggi dibandingkan dengan beberapa kabupaten dan kota lainnya, petani yang ada di Kabupaten Parigi Moutong khususnya petani Kecamatan Toribulu masih menghadapi masalah klasik yang sering dihadapi oleh 
petani kakao dalam 5 tahun terakhir yaitu rendahnya produktivitas tanaman kakao. Secara umum tanaman kakao memiliki potensi produktivitas sebesar $2000 \mathrm{~kg} / \mathrm{ha} /$ tahun namun produktivitas kakao rakyat di Kabupaten Parigi Moutong masih sangat jauh dari rata-rata potensi yang diharapkan hanya sebesar $898 \mathrm{~kg} / \mathrm{ha} / \mathrm{th}$. Penurunan produksi kakao berdampak pada nilai ekspor kakao Sulawesi Tengah yang menurun.

Produktivitas kakao dalam beberapa tahun terakhir masih rendah disebabkan oleh teknik produksi yang belum intensif, terutama berkaitan dengan penggunaaan bahan tanam yang tidak jelas asal usulnya, petani tidak melakukan pemupukan, belum memahami teknik pengendalian hama dan penyakit, pemangkasan dan naungan. Selain itu juga disebabkan oleh serangan hama Penggerek Buah Kakao (PBK) Conophomorpha cramerella Snellen yang dapat menyebabkan penurunan produksi 580\% (Anshary, A., 2002; Wahyudi et al, 2009), serangan hama tersebut menyebabkan kerugian yang harus ditanggung oleh petani baik secara sosial ataupun ekonomi dapat ditaksir mencapai 50 juta rupiah per hektar (Anshary, 2001).

Upaya yang dapat dilakukan dalam meningkatkan kualitas dan kuantitas produksi biji kakao dengan menerapkan pengendalian hama Penggerek Buah Kakao dengan menggunakan bahan kimia, cara budidaya, dan fisik mekanik, system PsPSP, namun upaya tersebut belum memberikan hasil yang maksimal, dan justru pengendalian dengan cara kimia diduga telah menimbulkan masalah pencemaran lingkungan, residu bahan kimia dalam biji kakao yang tinggi serta munculnya fenomena resistensi serangga terhadap pestisida (Tim Pelaksana $\left.\mathrm{I}_{\mathrm{b}} \mathrm{W}, 2012\right)$. Oleh karena itu telah diupayakan bentuk kegiatan yang sifatnya ramah lingkungan dan aman untuk konsumen melalui proses transformasi ilmu dan teknologi yang dilakukan dengan model pelatihan, demplot dan pendampingan selama beberapa bulan dalam perkebunan kakao rakyat yang memiliki daya saing
Kelompok petani kakao "Sinar Kasih dan Sinar Harapan" dibawah binaan GAPOKTAN Bina Karya Bakti di Desa Sibalago dengan secara aktif melakukan kegiatan pemeliharaan tanaman kakao dalam rangka untuk memperoleh peningkatan pendapatan dari sektor tanaman perkebunan khususnya tanaman kakao. Setiap kelompok memiliki anggota sebanyak 25 orang, setiap anggota memiliki luas perkebunan kakao seluas 2-3 hektar per orang. Melalui program ini, dari sembilan kelompok yang bernaung dibawang Gapokta Bina Karya Bakti yang memiliki anggota sebanyak 225 orang. Melalui kegiatan ini kami dari tim PKM telah menangani dan meningkatkan pengetahuan serta keterampilan mereka yang tergabung dalam dua kelompok tersebut. Peningkatan kualitas dan kuantitas produksi kakao telah dapat ditingkatkan melalui pemeliharaan kakao dan teknik pengendalian yang ramah lingkungan dan berkelanjutan dan menghasilkan biji kakao yang mutu dan berdaya saing. Dengan demikian anggota yang terlibat, akan mentrasfer dan mensosialisasikan pengetahuan dan keterampilan kepada sesama anggota yang diterima selama pelatihan dan pendampingan.

Pemeliharaan kakao masih dilakukan secara tradisional tetapi bila dibarengi dengan menggunakan beberapa teknologi pengendalian secara terpadu diantaranya pengendalian hayati dengan memanfaatkan semut, laba-laba, dan trichogramma, pengendalian PsPSP, pengendalian fisik dan mekanik, pengendalian dengan sistem kultur teknis, pengendalian Fero Trap PBK, diharapkan dapat meningkatkan kuantitas dan mutu kualitas kakao yang memiliki daya saing, standar ekspor (Ditjebun,2010).

Program Kemitraan Masyarakat ini telah mengatasi beberapa persoalan petani dalam mengatasi serangan OPT tanaman kakao di Desa Sibalago. Kegiatan yang dilakukan secara terpadu ini, memantapkan produksi kakao dengan menerapkan pengendalian OPT secara terpadu pada petani kakao di Desa Sibalago melalui metode Sekolah Lapang, Pelatihan atau Penyuluhan, 
Demplot, dan Pendampingan. Kegiatan ini telah dapat mencegah terjadinya pencemaran lingkungan dari akibat penggunaan bahan kimia, baik dengan penggunaan pestisida kimia maupun penggunaan pupuk kimia. Selanjutnya target luaran dari kegiatan PKM ini adalah : 1.Peningkatan keterampilan sumber daya manusia anggota kelompok tani kakao di Desa Sibalago tentang teknologi pemeliharaan kakao. 2. Meningkatnya inovasi teknologi pengendalian hama PBK, Helopelthis dan penyakit busuk buah kakao. 3. Meningkatnya produksi kakao melalui transformasi teknologi pemeliharaan kakao secara terpadu. 4.Peningkatan ketentraman/kesehatan masyarakat (mitra masyarakat umum), berkaitan dengan dampak penggunaan pestisida secara berlebihan 5.Publikasi ilmiah di jurnal dan media massa cetak

\section{Sumber Inspirasi}

Potensi produksi kakao di Kabupaten Parigi Moutong, khususnya di desa Sibalogo Kecamatan Toribulu sangat menjanjikan, bukan saja karena luasnya areal pertanaman kakao, namun juga masyarakat pada umumnya adalah petani kakao yang memiliki semangat dan motivasi yang cukup tinggi dalam meningkatkan produktivitas pertanaman kakao. Hal ini terbukti dengan berbagai upaya pengendalian dilakukan petani untuk menekan kerusakan akibat masih tingginya serangan Organisme Pengganggu (OPT). Tehnik pengendalian yang umumnya digunakan adalah dengan bahan kimia (pestisida). Faktor penting yang mempengaruhi petani dalam pengendalian OPT di desa Sibalogo adalah perilaku yang dipengaruhi adanya internal conflic antara pemenuhan kebutuhan dan kendala usahanya akibat gangguan hama yang hebat dan orientasi petani kakao masih sebatas produksi tanpa mempertimbangkan aspek keselamatan lingkungan. Oleh karena itu, perilaku petani dalam pengendalian hama yang berbasis ekosistem perlu ditingkatkan dan dilakukan pembinaan serta pendampingan. Pengetahuan petani petani kakao di desa Sibalago Kabupaten Parigi Moutong sebagai pelaku utama dalam mengelolah sumber daya alam perlu ditingkatkan guna keberlanjutan pertanian pada masa yang akan datang .

\section{Metode}

Guna mencapai target luaran yang diinginkan, maka metode yang diterapkan dalam kegiatan PKM ini adalah metode dengan pendekatan PRA (Participatory Rural Appraisal) dalam menyelesaikan dan memecahkan permasalahan yang dihadapi oleh kelompok. Setiap permasalahan yang muncul dianalisis dan dipecahkan secara bersama anggota kelompok yang terlibat dalam kegiatan ini. Dalam mencapai keberhasilan, pola Sekolah Lapang (SLPHT) digunakan sebagai alternatif dalam mendorong perkembangan paradigma petani dengan pendekatan pemberdayaan dan peningkatan kualitas sumber daya manusia.

$$
\text { PKM Pemberdayaan Kelompok }
$$

Petani Kakao Melalui Penerapan Metode SLPHT Di Desa Sibalago dimulai dilaksanakan Maret 2018 hingga Nopember 2018 dengan berbagai tahapa, yaitu; tahapan persiapan, tahapan pelaksanaan dan tahapan evaluasi kegiatan. Pada tahapan persiapan dilakukan rapat persiapan kegiatan dengan anggota tim berupa penyusunan materi pelatihan dan koordinasi dengan PPL setempat, sosialisasi pemahaman dan pengertian dasar prinsip-prinsip Pengendalian Hama Terpadu (PHT), tehniktehnik pengendalian OPT yang dapat digunakan selain pestisida. Tahapan pelaksanaan kegiatan PKM dilakukan dengan metode sekolah lapang (SLPHT) yang diawali dengan pemberian penyuluhan dalam bentuk ceramah, tanya jawab, diskusi. Adapun materi penyuluhan adalah Rehabilitasi tanaman kakao, pengelolaan hama dan penyakit secara terpadu, Penanganan pasca panen buah kakao dengan sistem fermentasi, Menumbuh kembangkan Lembaga Ekonomi Petani yang dapat menunjang adopsi teknologi secara berkelanjutan dan Sistem manajemen organisasi, manajemen usaha kecil, dan manajemen pemasaran. Kegiatan SLPHT 
dilakukan dengan melibatkan langsung petani dalam kegiatan pembuatan Bioinsektisida yang berbahan dasar Beauveria bassiana dan Jamur Trichoderma sp, dan melakukan analisis ekosistem tanaman kakao dan siklus hidup penggerek buah kakao (PBK) lalu dipersentasekan di depan kelompok lain. Demikian halnya dalam teknik perbanyakan beberapa musuh alami diantaranya perbanyakan semut hitam dan sarungisasi serta pembuatan pupuk organik dari limbah kakao dan limbah pertanian lainnya dengan dekomposer Trichoderma sp. Sedangkan pada tahapan evaluasi kegiatan PKM meliputi evaluasi input, proses, produk dan kepuasan anggota kelompok mitra terhadap kegiatan yang dilakukan oleh Tim PKM Unisa Palu.

\section{Hasil dan Pembahasan}

\section{a. Kegiatan Pemberian Materi}

Kegiatan pemberian materi dilakukan dengan ceramah dan tanya jawab yang meliputi pemahaman tentang rehabilitasi tanaman kakao dan pengertian dasar prinsipprinsip Pengendalian Hama Terpadu (PHT) serta tehnik-tehnik pengendalian OPT yang dapat digunakan selain pestisida. Pada hakekatnya kedua kelompok mitra sudah mengetahui tentang beberapa jenis OPT yang menyerang tanaman kakao mereka, berikut pengendalian kimia digunakan, namun dengan adanya PKM ini maka mereka lebih memahami filosofinya rehabilitasi tanaman kakao dan prinsip-prinsip PHT guna keberlanjutan pertanian pada masa yang akan datang. Selama ini mereka hanya mengenal budidaya tanaman dan kakao secara sederhana dan pengendalian secara kimia, dengan adanya PKM ini, maka mereka lebih mengetahui tentang adanya metode pengendalian hama yang lebih ekonomis, aman dan bisa diapilikasikan dengan mudah. Antusias peserta dalam kegiatan penyuluhan ini demikian tinggi, karena menyangkut kepentingan mereka, sehingga proses tanya jawab berlangsung cukup lama dan menarik terkait pertanyaan seputar budidaya, pengendalian OPT dan pasca panen tanaman kakao oleh petani kepada narasumber.

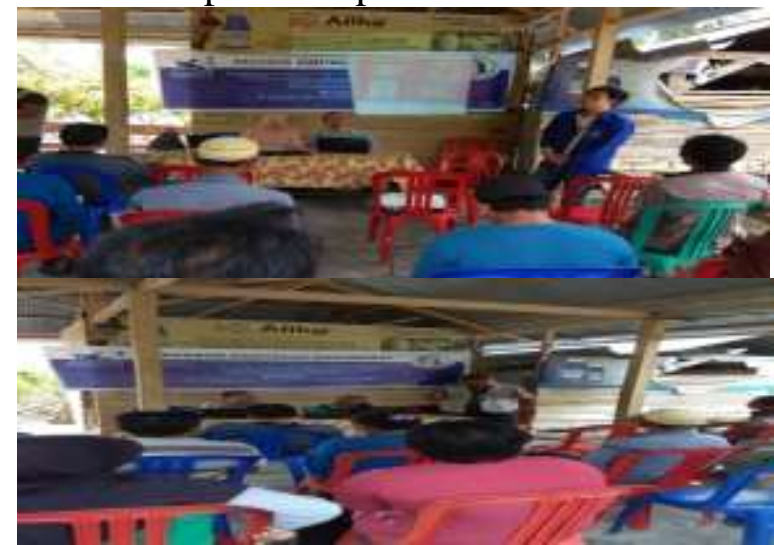

Gambar 1. Kegiatan Penyuluhan kepada Petani

b. Kegiatan Pembuatan Biopestisida yang berbahan dasar Beauveria bassiana dan Jamur Trichoderma sp

Kegiatan pembuatan Biopestisida berbahan dasar Beauveria bassiana dan Jamur Trichoderma sp dilakukan dengan terlebih dahulu menyiapkan media tumbuh berupa jagung giling yang telah dicuci sampai bersih dan dikukus selama 30 menit, lalu dikeringanginkan sampai dingin. Selanjutnya jagung giling yang sudah dingin dimasukkan kedalam plastik tahan panas. Tiap plastik berisi 30 sampai 50 gram jagung giling, lalu mulut plastic ditutup atau diikat kemudian disterilkan dalam pemanas dengan suhu $120^{\circ} \mathrm{C}$ selama 1-2 jam. Setelah dingin diambil satu sendok biakan Trichoderma sp lalu diinokulasikan ke dalam media jagung giling tersebut kemudian dibiarkan sekitar 10-21 hari. Proses pembuatan bioinsektisida dilakukan bersama petani kakao, mulai dari tahapan penyediaan media hingga proses inokulasi. Antusias petani dalam pembuatan biopestisida, terlihat saat mereka berdiskusi dan menanyakan tentang bagaimana menyimpan, menggunakan dan memperbanyak agen hayati ini. 


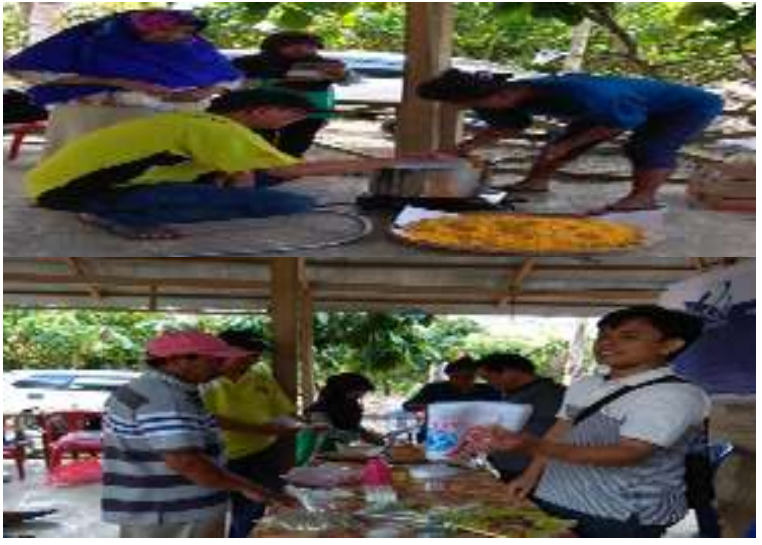

Gambar 2. Kegiatan pembuatan media tumbuh Trichoderma $s p$

c. Kegiatan Sekolah Lapang dan Pembuatan Pupuk Organik

Metode yang diterapkan dalam demonstrasi percobaan sekaligus aplikasi menggunakan metode sekolah lapang yang mencakup analisis ekosistem tanaman kakao dan siklus hidup Penggerek Buah Kakao (PBK). Pelaksanaan kegiatan ini diawali dengan pembagian kelompok kerja dari seluruh peserta. Peserta dibagi menjadi 2 (dua) kelompok besar agar setiap kelompok kerja lebih mudah untuk dibimbing dan dibina terutama yang berkenaan dengan materi pelatihan. Hasil analisis masingmasing kelompok kemudian diperentasekan di depan kelompok lain. Selama ini mereka hanya membudidayakan tanaman kakao tetapi belum memahami sepenuhnya bagaimana dan kenapa diperlukan perawatan tanaman kakao berikut ekosistem tanaman kakao itu sendiri dan bagaimana PBK menyerang tanaman kakao sampai menimbulkan serangan. Hal ini mereka peroleh setelah melakukan analisis ekosistem dan diskusi kelompok melalui kegiatan PKM ini.

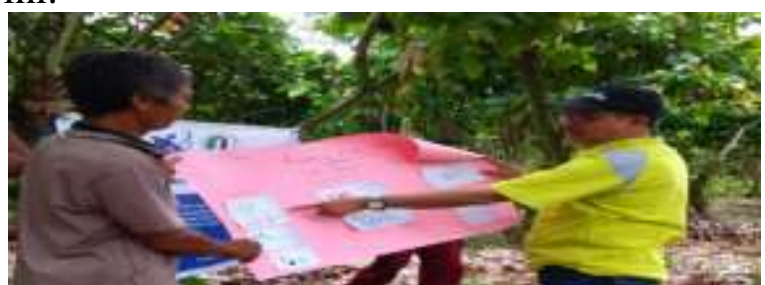

Gambar 3. Petani memperlihatkan hasil diskusi kelompoknya

Selanjutnya petani pada kelompok masing-masing melakukan praktek langsung pengendalian PBK, dengan memfaatkan semut hitam ( Dolichoderus thoracicus). Pengendalian dengan semut hitam meruapakan salah satu teknik pengendalian dengan memanfaatkan musuh alami (eksosistem). Untuk itu masing-masing kelompok melakukan perbanyakan semut hitam, dengan cara membuat sarang buatan berupa batang bamboo (diameter $8-10 \mathrm{~cm}$ dan panjang $40 \mathrm{~cm}$ ) dibuat dengan cara memotong batang bamboo sepanjang satu ruas yaitu dari pangkal ruas sampai dengan ujung ruas berikutnya sehingga ujung satu tertutup dan yang lainnya terbuka atau berlubang. Selanjutnya pada sarang bambu tersebut dimasukkan daun kelapa kering kemudian diberikan gula merah yang diencerkan dalam aquades dengan konsentrasi 10 persen sebanyak 1 sendok makan dengan cara mengoleskan pada permukaan luar dan didalam sarang. Bambu yang sudah tersedia sarang tadi diikatkan pada bagian dahan tanaman kakao.

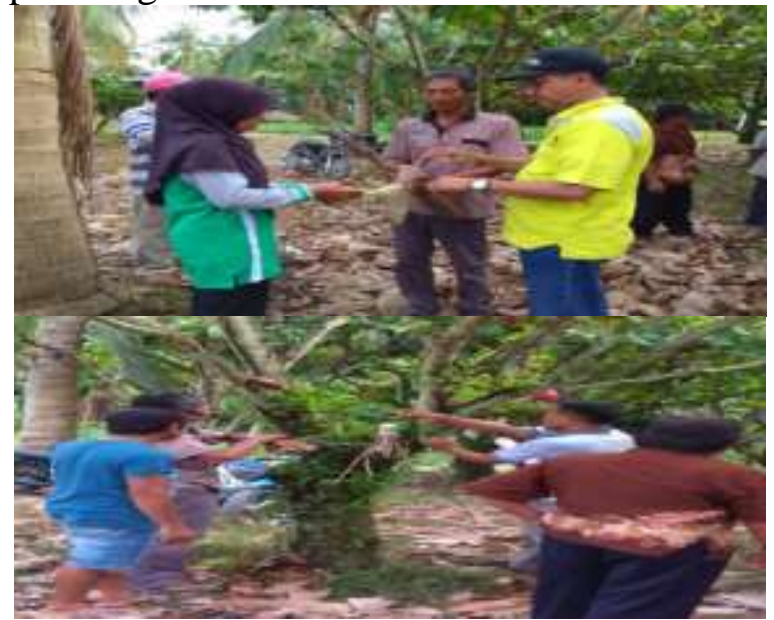

Gambar 4. Pembuatan sarang dan perbanyakan semut hitam

Salah satu faktor penting yang dapat mendukung perbaikan fisik maupun kimia tanah adalah dengan manfaatkan limbah kakao yang tersedia cukup banyak sebagai pupuk organik. Dalam kegiatan PKM ini telah dilatihkan kepada kelompok tani tentang cara pembuatan Pupuk organik dengan memanfaatkan kulit buah kakao dan limbah hasil pertanian lainnya dengan menambahkan dekomposer jamur trichoderma sp yang juga telah dilatihkan 
cara memperbayakannya untuk mempercepat proses dekomposisi.

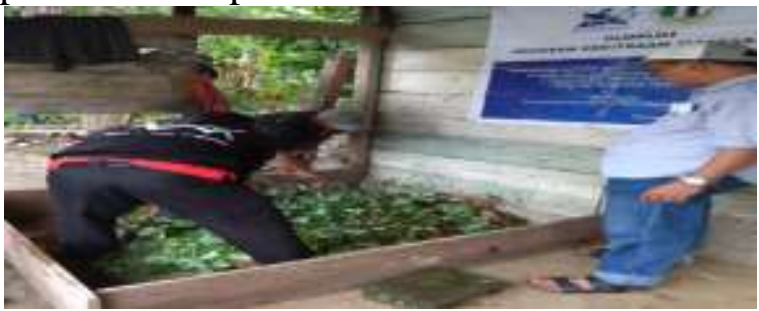

Gambar 5. Pembuatan Pupuk Organik Limbah Kakao

\section{Dampak dan Mafaat Kegiatan}

Dampak dari kegiatan PKM ini bagi mitra, dua kelompok tani di desa Sibalago adalah;

1. Peningkatan pemahaman kepada kelompok Mitra untuk dapat mengetahui tentang rehabilitasi tanaman kakao, pengendalian OPT yang sesuai dengan prinsip-prinsip PHT, dengan keterampilan yang dimiliki dalam memperbanyak jamur trichoderma sp dan memperbanyak semut hitam di lapangan.

2. Peningkatan pengetahuan dan keterampilan dalam pembuatan pupuk organik dengan pemanfaatan limbah kakao dengan menambahkan dekomposer jamur trichoderma sp untuk mempercepat proses dekomposisi.

3. Meningkatnya produksi kakao karena adanya penguasaan teknologi pemeliharaan kakao secara terpadu.

4. Peningkatan pemahaman tentang dampak penggunaan pestisida secara berlebihan, dan adanya solusi alternatif pengendalian OPT yang lebih ramah lingkungan.

\section{Kesimpulan}

Dari hasil kegiatan pengabdian masyarakat berupa PKM,dapat diambil beberapa kesimpulan yakni; 1. Kedua kelompok Mitra di desa Sibalago memiliki keiinginan yang kuat untuk meningkatkan produksi tanaman kakaonya, hanya saja selalu terkendala dengan adanya serangan Organisme Pengganggu Tanaman (OPT). Olehnya respon yang positif diberikan Mitra terhadap kegiatan PKM, terbukti dengan begitu antusias mengikuti kegiatan tahapan demi tahapan kegiatan PKM ini. 2. Kedua kelompok mitra juga telah memahami filosofi dari ekosistem budidaya tanaman kakao dan siklus hidup Penggerek Buah Kakao (PBK) 3. Kedua kelompok mitra telah memahami tentang pengendalian OPT dengan memanfaatkan agen hayati berupa Trichoderma sp dan semut hitam (Dolichoderus thoracicus) serta telah mampu melaksanakan dengan baik kegiatan pembuatan pupuk organik dengan pemanfaatan limbah kakao dengan menambahkan dekomposer jamur trichoderma sp untuk mempercepat proses dekomposisi.

\section{Ucapan Terima Kasih}

Terima kasih disampaikan kepada Rektor, Dekan Fakultas Pertanian dan Ketua LP2M Unisa Palu dan Teman-teman Di Fakultas Pertanian Unisa Palu, atas kerjasamanya dan bantuannya selama kegiatan ini berlangsung. Demikian hal kepada ketua dan anggota kelompok Mitra di desa Sibalago atas respon yang positif terhadap kegiatan ini, Pak Arfan, S.P, Kepala penyuluh pertanian kecamatan Toribulu dan Ibu Sulastri,S.P sebagai PPL di di desa Sibalago. Ucapan yang sama kami haturkan kepada Direktur penelitian dan Pengabdian Kepada Masyarakat Kementerian Riset Teknologi dan Pendidikan Tinggi atas bantuan pendananaan kegiatan ini sesuai Perjanjian Pelaksanaan Penugasan Program Pengabdian kepada Masyarakat tanggal 27 Maret 2018

\section{Daftar Pustaka}

Anshary, A., 2001. Perlu Keterpaduan Dalam Pengelolaan Hama PBK Conopomorpha cramerella Snell (Lepidoptera: Gracillariidae) di Sulawesi Tengah. Harian Mercusuar. Edisi September 2001.Palu Sulawesi Tengah.

Anshary, A., 2002. Karakteristik Tanaman Kakao (Theobroma cacao L) yang Tahan Terhadap Penggerek Buah Kakao Conopomorpha cramerella Snell (Lepidoptera: Gracillariidae). Program Pasca Sarjana Universitas Hasanuddin, Makassar. 
Abditani : Jurnal Pengabdian Masyarakat 1 (1) 1-7

Ditjenbun, 2000.Kebijakan Pengembangan Kakao Indonesia. Simposium Kakao 2000. 26-27 September 2000. Surabaya, Puslitloka.

Ditjenbun, 2010. Panduan Teknis Budidaya Tanaman Kakao (Theobroma cacao,L). USAID, AMARTA dan PPKI,Jakarta.

Deptan RI., 2005. Statistik Pertanian. Departemen Pertanian. Jakarta.

Tim Pelaksana $\mathrm{I}_{\mathrm{b}} \mathrm{W}$ Kecamatan Dolo Selatan 2012. Pembuatan Bioinsektisida Berbahan Aktif Beauveria bassiana dan Trichoderma sp. Untuk Memenuhi Ketersediaan Bahan Pengendali OPT Bagi Petani, LPM Universitas Tadulako dan LPM Universitas Alkhairaat Palu.

Tim Pelaksana $\mathrm{I}_{\mathrm{b}} \mathrm{W}$ Kecamatan Dolo Selatan 2012. Teknologi Pembuatan Bokasi Limbah Kulit Buah Kakao. LPM Universitas Tadulako dan LPM Universitas Alkhairaat Palu.

Tim Pelaksana $\mathrm{I}_{\mathrm{b}} \mathrm{W}$ Kecamatan Dolo Selatan 2012. Pengendalian Hama Penggerek Buah Kakao (PBK) dengan Predator Dolichoderus Thoracicus., LPM Universitas Tadulako dan LPM Universitas Alkhairaat Palu.

Wahyudi T., T.R. Panggabean., Pujiyanto., 2009. Panduan Lengkap Kakao Manajemen Agribisnis dari Hulu hingga Hilir. Penebar Swadaya, Jakarta. 